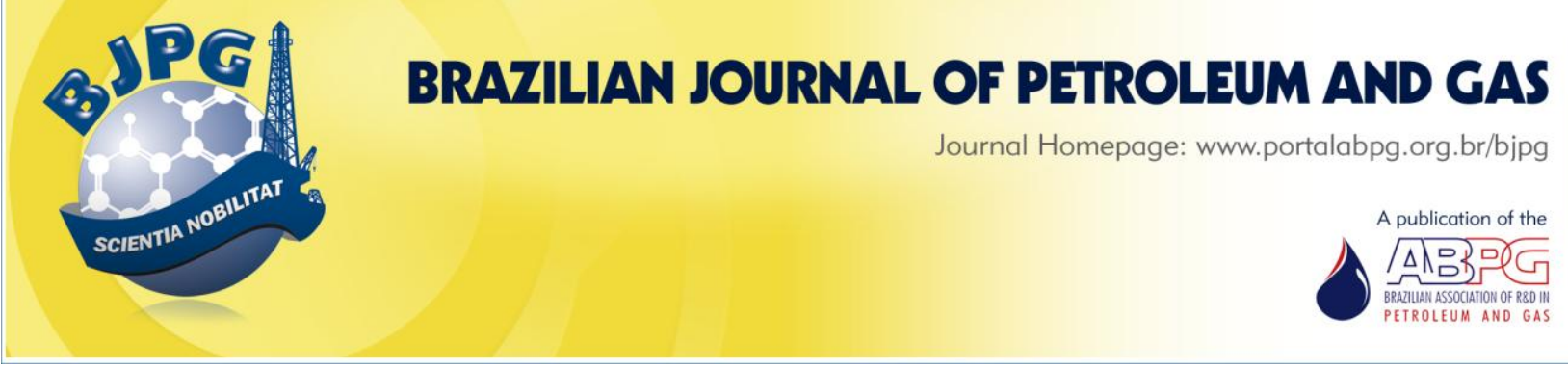

\title{
EXPERIMENTAL MEASUREMENT OF GAS-LIQUID DIFFUSIVITY
}

\author{
${ }^{\text {a }}$ Policarpo, N. A. ${ }^{1} ;{ }^{\text {a }}$ Ribeiro, P. R. \\ ${ }^{a}$ Department of Petroleum Engineering, Universidade Estadual de Campinas (UNICAMP), Brazil
}

\begin{abstract}
The discovery of giant oil fields in the sub-salt zone has been pointed out as a new phase in the energetic scenario in Brazil and around the world. In order to assure hydrocarbon exploitation in those areas, an intense development in science and technology is necessary. The study of the interaction between operation and formation fluids is essential to assure safety during drillings and completion of the well. The possibility of blowouts during drilling, completion, and well intervention must be eliminated. Measurement, interpretation and modeling of the fluid mixture behavior, under reservoir conditions and well-control operations, can contribute to prevent blowouts. In this context, some thermodynamic aspects of formation gas and drilling fluid under reservoir conditions are presented. Additionally, this paper focuses on current experimental methods and data modeling applied to evaluation of gas-liquid diffusivity, giving special attention for the method that uses PVT thermodynamic cells.
\end{abstract}

\section{KEYWORDS}

gas-liquid mixtures; petroleum; diffusivity; well control; drilling

\footnotetext{
${ }^{1}$ To whom all correspondence should be addressed.

Address: Department of Petroleum Engineering, Faculdade de Engenharia Mecânica, Universidade Estadual de Campinas (UNICAMP), Caixa Postal 6122, Campinas, SP, Brazil CEP: 13083-970|Telephone: (55) 1935213367 |e-mail: npolicarpo@yahoo.com doi:10.5419/bjpg2011-0017
} 


\section{INTRODUCTION}

The recent discovery of giant oil fields in the sub-salt zone has been pointed out as a new phase on the global energy scenario. In order to assure hydrocarbon exploitation in those areas, there is a need to intensify scientific and technological research and development efforts. This demand is confirmed by geophysical and exploratory drilling data, which indicates the major challenges in the development of fields, particularly in the well engineering one.

Drilling wells in sea areas, of extensive water depths and wide layers of salt, to reach the production in the sub-salt zone, at depths ranging from 6000 to $8000 \mathrm{~m}$, requires the development of innovative materials, new drilling fluids and completion to support the harsh conditions of pressure (around 10,000 to 20,000 psi) and temperature (up to $200 \circ \mathrm{C}$ ) downhole. Moreover, it is crucial to develop advanced techniques of well drilling and completion. Within the context of drilling and completion, the study of the interaction between the operating fluid and the production zone is essential to diagnose operational quality standards, particularly from the standpoint of operational safety.

Drilling fluids play a key role in well engineering. One of drilling fluid main function is to maintain the pressure inside the well greater than the pressure in the formation. If the fluid pressure is smaller than the formation pore pressure's one, it may occur a kick, that is, an influx of undesirable formation fluids (gas, oil, or water) inside the well. Once a kick is detected, the well should be shut down, and the invading fluid must be circulated out of it to prevent a blowout.

The blowout consequences are extremely disastrous. It may include human injuries, significant financial losses, and negative environmental impact. One example of this situation was the recent event (April 20, 2010) at the Deepwater Horizon platform operated by British Petroleum (BP), located in the Gulf of Mexico. In the accident, 11 workers were killed and 17 wounded. Moreover, the well spilled $5000 \mathrm{bpd}$ of oil into the sea, characterizing the event as the largest environmental accident in U.S. history, with billions of dollars of financial loss to BP, including the cleanup of the contaminated area (Brenner et

\section{al. 2010; CNN Wire Staff, 2010).}

Thus, the occurrence of blowouts during drilling, completion, and future interventions should be eliminated through measurements, interpretations, and modeling the appropriate behavior of fluid mixtures under reservoir conditions and the eventual operation of well control. Such information, when obtained, can be implemented in simulators that predict the occurrence of kicks.

These kick simulators should be reliable, representing a real situation and, therefore, should include a large number of physical variables to create a true representation of a real situation, as well as the trajectory and location (onshore or offshore), well control method, and behavior of the fluids involved (rheology, flow pattern, gas solubility in drilling fluid, and mass transfer among phases) (Avelar et al., 2009).

In this context, this article presents a review of the behavior of gas-liquid mixtures to serve as a reference for those needing to expand their knowledge about the topic. Additionally, this study focuses on experimental methods and data modeling applied to an estimative of gas-liquid diffusivity, giving special attention to the method that uses PVT (pressure, volume, and temperature) thermodynamic cells.

\section{LITERATURE REVIEW}

The literature review provides a brief introduction regarding drilling fluids and its functions in well drilling. Then, a research involving mass transfer of gas-liquid systems will focus on methods that use PVT thermodynamic cells for data measuring, and how these data are modeled. Finally, there will be a discussion of papers that address the thermodynamic aspects of these kinds of system.

\subsection{Drilling fluids}

Drilling fluids are a complex mixture of chemical compounds, basically composed by a continuous phase (liquid or gas), chemical additives, and clay. In drilling operations, these fluids perform numerous functions such as removing cuttings from the well, cooling and lubricating the bit and the drill string, maintaining well stability, and, 
mainly, exerting hydrostatic pressure on formation to prevent the influx of formation fluids into the wellbore.

During drilling, gases from the formation can be mixed with the drilling fluid. This contact can be caused by failures in the operation, such as insufficient fluid weight and circulation loss. Those failures can result in a negative gradient of pressure between drilling and formation fluids, causing a kick. To detect a gas kick through simulators, it is essential to know thermodynamic and diffusive interactions between formation and drilling fluids.

Fluid behavior properties, as a function of pressure, volume, and temperature, such as solubility of gas in liquid, specific gravity, and formation volume factor are provided by thermodynamic data. The velocity, in which the gas runs through the liquid until reaching the equilibrium, is given by mass transfer parameters.

Therefore, thermodynamic and mass transfer measurements in formation and drilling fluid system on real conditions, for example, under severe conditions, which are well characteristics discovered recently, are crucial to predict the risk of fluid influx into the well. The next section will show how gas-liquid mass transfer and thermodynamics work, in light of the problematic of drilling wells.

\subsection{Experimental methods for the gas- liquid diffusivity}

Mass transfer is a transport phenomenon that occurs due to concentration gradient of a substance in a given medium. According to Fick's First Law, the diffusivity is a constant of proportionality between the mass flux of specie $A$ in B and its spatial concentration gradient. Diffusivity of gas-liquid systems is the most important factor to determine the transfer rate of species from one phase to another. For this kind of system, there are many theories that support the phenomenon, and several correlations have been developed for molecular diffusivity calculation, which come mainly from Stokes-Einstein correlation (Jamialahmadi et al., 2006).

Experimentally, the mass transfer coefficient, the diffusivity coefficient, the equilibrium pressure, and the solubility are the most important process parameters. However, the characterization of the mass transfer process requires two important decisions: (i) to define a reliable experimental method; and (ii) to choose accurate models for data interpretation.

The conventional experimental methods used in diffusivity determination are classified into direct, when the composition of the liquid samples with gas absorbed is analyzed during the test, and indirect, when the composition of the liquid phase after diffusion is correlated with a measured system property. Both conventional methods are usually expensive because they require an analysis of the composition of system components, take a long time, and are susceptible to experimental errors (Upreti, 2000). Hence, it is necessary to develop simpler methods.

The nonconventional experimental methods for measuring diffusion parameters without needing to measure compositions are:

- The pressure decay (PD) method. It is the method where the pressure of the gas phase is measured as a function of time. Volume and temperature are held constant. The diffusivity coefficient is determined from the pressure decay data (Riazi, 1996; Sachs, 1998; Zhang et al., 2000; Sheikha et al., 2005);

- The constant pressure dissolving gas volumes (CPDGV) method. This method is similar to PD method but, in this case, volume-time data is recorded with constant pressure and temperature. After, the diffusivity is obtained from these data (Renner, 1988; Jamialahmadi et al., 2006);

- The low-field nuclear magnetic resonance (NMR) method. It is based on NMR spectra changes caused by changes in the mixture's properties with the diffusion process. So, these spectra changes are correlated to the concentration and mass transfer rate using Fick's Second Law (Wen and Kantzas, 2005);

The X-ray computer assisted tomography (CAT). This method is a common tool used in reservoir rock characterization, where the cross-sectional images of the diffusion cell are generated and a density profile of 


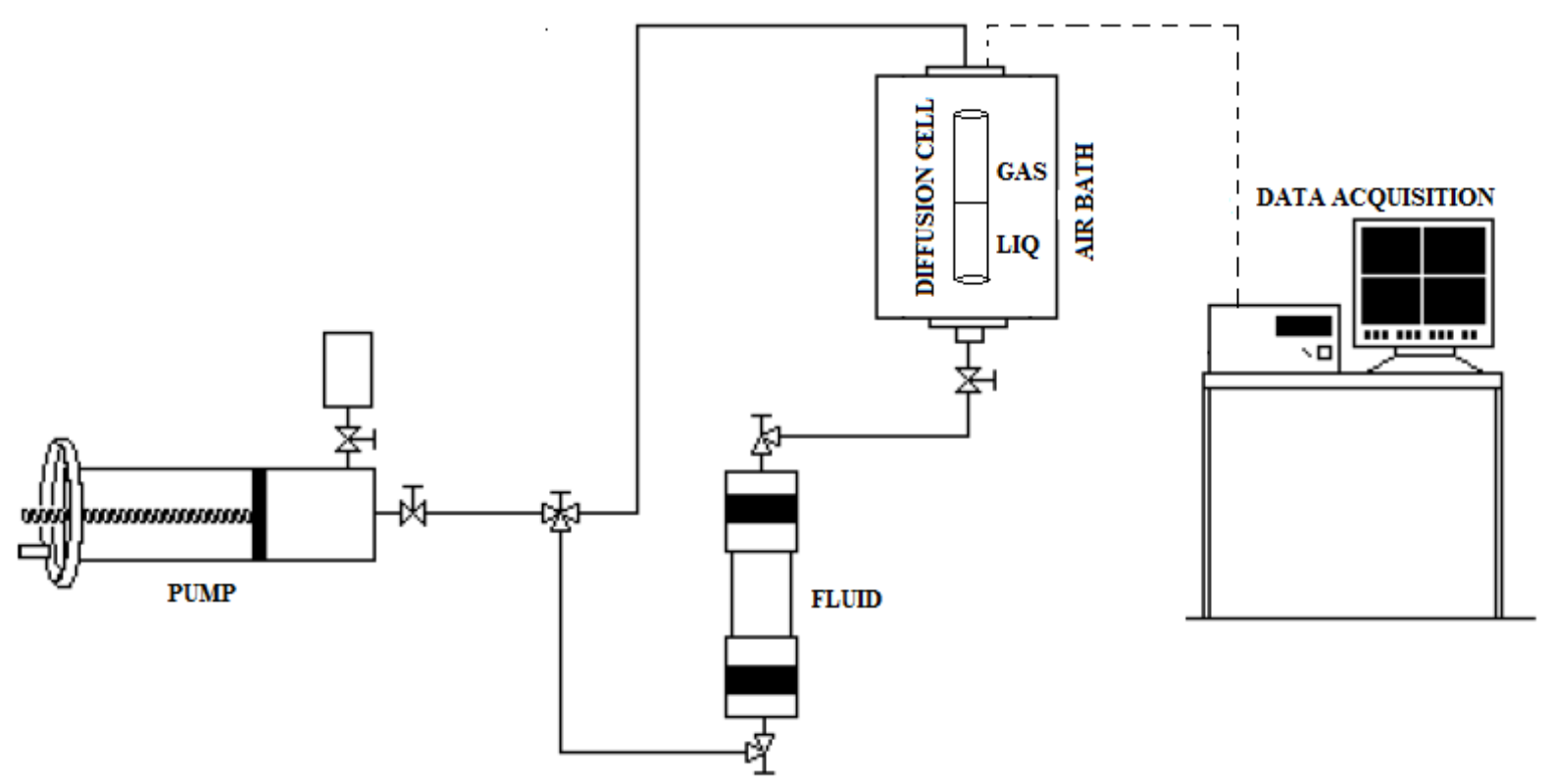

Figure 1. Experimental set-up of PVT cell for diffusivity measuring of gases in liquids.

the mixture is obtained. Then, the concentration profile of the mixture is also known and correlated to diffusivity through Fick's Law (Guerrero-Aconcha and Kantzas, 2009);

- The gas permeation through immobilized liquid membrane (ILM) method. It measures the pressure decay of gas entering in a closed chamber with a thin layer of ionic liquid. The diffusivity is obtained through pressure decay data using Fick's Law (Moganty and Baltus, 2010);

- $\quad$ The dynamic pendant drop volume analysis (DPDVA) method. This method is based on measuring the change in volume of a pendant oil drop in a cell surrounded by a gas that is absorbed by the drop with the diffusion process. The volume changes are analyzed through images captured and processed according to digital analysis techniques (Yang and Gu, 2005).

Each method mentioned above has its peculiarities. NMR and CAT are methods that require expensive devices and technical specialists to handle it. The DPDVA is useful to calculate the swelling coefficient of the liquid phase because the effect is amplified due to liquid drop size. Although the PD method took a long period of time to attain the equilibrium state of the mixture, the technique avoid errors in parameters calculations by using large size samples in the experiments, which give a good accuracy of the results (Rasmussen and Civan, 2009). For the reasons listed above, the PD is the method that will be focused in this article.

\subsubsection{Pressure Decay Method - PD}

Among the methods mentioned, the PD is the most used because of its convenience, simplicity, and accuracy. The PD was developed by Riazi (1996), whose results obtained by this method for methane $\left(C_{1}\right)$ and n-pentane $\left(n-C_{5}\right)$ system yielded binary mixture diffusion coefficients around $\pm 5 \%$ of literature values. In this method, the pressure of the gas phase is recorded along with time, as the molecular diffusion occurs from the gas to liquid phase to achieve equilibrium (saturation). The experiment is usually carried out in a PVT cell similar to the one used in this work, as shown in Figure 1. The experimental apparatus is composed by a hydraulic pump, fluid bottles, diffusion cell, and data acquisition system.

The main goal of Riazi (1996) was to develop a model that could predict the position of the gasliquid interface and the gas pressure as a function of time in a PVT cell, at constant volume and temperature, in order to understand the 


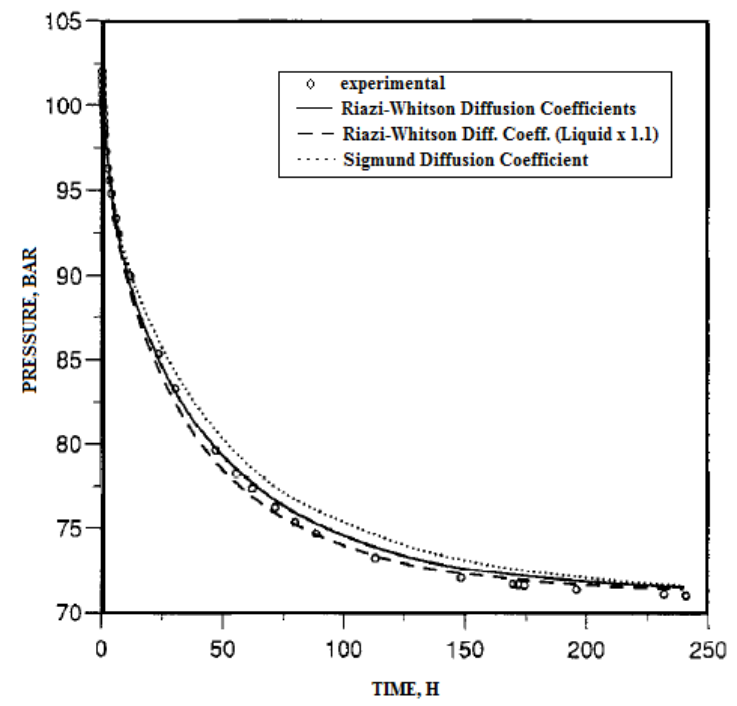

Figure 2. Pressure as a function of time at constant volume for $\mathrm{C}_{1}-\mathrm{nC}_{5}$ at $37.8^{\circ} \mathrm{C}$ (Riazi, 1996).

importance of diffusive processes in oil recovery techniques. The author tested a methane-npentane system at an initial pressure of $10200 \mathrm{kPa}$ and at a temperature of $37.8{ }^{\circ} \mathrm{C}$. The cell was initially filled with $35 \%$ by volume of liquid $n$ pentane. The experimental results for the diffusivity of this system were compared to published data according to Figure 2. The author concluded, from the satisfactory match among the model's results and the experimental data, that the diffusive process is dominant in this kind of mass transfer experiments.

Riazi (1996) used Fick's Second Law (Equation 1) to describe diffusion process. The diffusion coefficient was corrected by a thermodynamic factor for non-ideal mixtures (Equation 2), at which it was considered that natural convection does not occur.

$$
\frac{\partial C_{o i}}{\partial t}=D_{o i} \frac{\partial^{2} C_{o i}}{\partial z_{0}^{2}}
$$

$$
D_{o i}=D_{o i}^{\prime}\left(1+\frac{\partial \ln \phi_{i}}{\partial x_{i}}\right)
$$

where $\phi_{i}$ is the fugacity coefficient of component $i$ in the mixture and $x_{i}$ is the mole fraction of $i$ in the liquid phase.

According to Riazi (1996), when the system reaches equilibrium, at $7100 \mathrm{kPa}$, the mole fraction of methane is 0.33 and the diffusion coefficient is $1.51 \times 10^{-8} \mathrm{~m}^{2} / \mathrm{s}$. In these conditions, the value obtained by the Riazi-Whitson's correlation was $1.37 \times 10^{-8} \mathrm{~m}^{2} / \mathrm{s}$ and Sigmund's correlation was $1.22 \times 10^{-8} \mathrm{~m}^{2} / \mathrm{s}$. The value obtained by the Riazi (1996) was the closest to the experimental value reported by Reamer-Duffy-Sage, which was $1.43 \times 10^{-8} \mathrm{~m}^{2} / \mathrm{s}$, with a deviation of $5 \%$.

Sachs (1998) studied a methane-water system focusing on the diffusion phenomenon. Sachs' emphasis choice can be explained by the fact that data related to this system were scarce in literature, especially at oil reservoir conditions. The author also used a PVT cell, similar to the one depicted in Figure 1 , to study the diffusion behavior of the system. Sachs (1998) used a different treatment for pressure-time data measured. The author tested three types of dependency relations between the solute concentration in the liquid phase and diffusivity coefficient from the Fick's Law. The three cases were: (i) admitted diluted system $\left(\phi_{i}=1\right)$; (ii) used the correction factor presented by equation (2), and (iii) used an equation $x_{i}=f\left(D_{A B}\right)$. The results of this study can be seen in Table 1 .

From these results, the author concluded that the dependence between the solute concentration in the liquid phase and diffusivity of methane-

Table 1. Diffusion coefficients $\left(D_{A B}\right)$ for methane-water system (Sachs, 1998).

\begin{tabular}{lcc}
\hline \multicolumn{1}{c}{ CASE } & $\mathbf{D}_{\mathrm{i}} \times \mathbf{1 0 ^ { - 9 }} \mathrm{m}^{\mathbf{2}} / \mathbf{s}$ & $\pm \Delta \mathrm{P}(\mathrm{kPa})$ \\
\hline (i) diluted system & 1.84 & 5.78 \\
(ii) correction factor & 2.07 & 3.16 \\
(iii) equation $\mathrm{x}_{\mathrm{i}}=f\left(\mathrm{D}_{\mathrm{AB}}\right)$ & 2.09 & 0.223 \\
\hline
\end{tabular}


water system can not be neglected and, therefore, the case (iii) was the best fit with a mean deviation of $\pm 0.223 \mathrm{kPa}$.

Using the method developed by Riazi (1996) for measuring diffusivity with an application to enhanced oil recovery (EOR), Zhang et al. (2000) studied the diffusion of two gases: methane $\left(\mathrm{CH}_{4}\right)$ and carbon dioxide $\left(\mathrm{CO}_{2}\right)$ in heavy oil (Hamaca oilVenezuela, viscosity of 5.0 Pa.s). The experiments were conducted at room temperature $\left(21^{\circ} \mathrm{C}\right)$, initial pressure of $3471 \mathrm{kPa}$ for methane-oil system and $3510 \mathrm{kPa}$ for $\mathrm{CO}_{2}$-oil, and final pressures of $3420 \mathrm{kPa}$ and $2856 \mathrm{kPa}$, respectively. For these values of pressure and temperature, the diffusivity coefficients obtained by Zhang et al. (2000) were $8.6 \times 10^{-9} \mathrm{~m}^{2} / \mathrm{s}$ and $4.8 \times 10^{-9} \mathrm{~m}^{2} / \mathrm{s}$ for the systems methane-oil and $\mathrm{CO}_{2}$-oil, respectively. For $\mathrm{CO}_{2}$-oil, the authors obtained a diffusivity coefficient close to that obtained by Nguyen and Farouq-Ali (1995), which was $3.2544 \times 10^{-9} \mathrm{~m}^{2} / \mathrm{s}$ for a similar system, under the same conditions of temperature and pressure, its oil had viscosity equal to $1.842 \mathrm{~Pa}$.s. Based on this, the authors concluded that the experimental method used to determine the diffusivity for these types of systems were satisfactory and simple.

During the experiment of Zhang et al. (2000), using the PD method, the gas pressure in the gas phase tends to drop due to the gas transfer to liquid phase. This transfer causes swelling of the liquid phase due to gas diffusion, causing the interface displacement. Beyond Zhang et al. (2000), other researchers did not monitor the gasliquid interface in the PVT cell, considering that the displacement of this interface is so small that is negligible. However, Yang and Gu (2005) got a liquid volume increase of $7 \%$ after $1200 \mathrm{~s}$, at 4 $\mathrm{MPa}$, and 23.9으, for $\mathrm{CO}_{2}$ and heavy oil. These researchers stated that, for $\mathrm{CO}_{2}$ immiscible flooding processes, the oil swelling is an important effect at increasing residual oil recovery. For well control operations, the swelling of oil-based drilling fluid caused by the absorption of formation gas in a kick situation is a mechanism that contributes strongly for the kick detection (Monteiro et al., 2009). Therefore, this mechanism should be evaluated carefully in well control problems.

To determine an accurate diffusivity coefficient, the experimental method should match with a proper mathematical modeling to avoid, as much as possible, inadequate simplifications such as the assumption of a constant compressibility factor of gas at high pressure situations, as Zhang et al. (2000) did. So, with the purpose of implementing a correct mathematical modeling for diffusion processes for gas-liquid mixtures, Civan and Rasmussen (2001; 2002; and 2003) developed a diffusive model for equilibrium and nonequilibrium situations, in a transient-state, to obtain data for the diffusion coefficient of formation gas and stated that the model should be applied to any gas when in contact with oil, brine, drilling, and completion fluids. Such papers encompass the same mathematical analysis, with short- and long-time solutions obtained analytically.

The equations were tested with the experimental data from Riazi (1996), Sachs (1998), and Zhang et al. (2000). Then, these equations were compared with the original data from those authors. The diffusivity results for the systems were different, in one order of magnitude, from those obtained experimentally by Riazi (1996), Sachs (1998), and Zhang et al. (2000), as can be seen in Table 2. According to Civan and Rasmussen (2003), this happens due to low accuracy of the models adopted with simplified assumptions by the researchers who measured the experimental data, although the results of these authors are subjected to errors associated with the unknown equilibrium pressure.

To solve the problem of unknown equilibrium pressure, Rasmussen and Civan (2009) developed a modification on mathematical modeling of their previous work. The modeling is based on pressure decay data with time-limited, without needing to carry on experiments until the equilibrium is reached. This analysis avoids the errors related to the late-time data caused by gas leaks and liquid swelling of the liquid phase. For the Sachs's (1998) system presented in Table 2, Rasmussen and Civan (2009) obtained better results for diffusivity coefficient than those shown in Civan and Rasmussen (2003). The diffusivity coefficient from Rasmussen and Civan (2009) were $1.406 \times 10^{-9} \mathrm{~m}^{2} / \mathrm{s}$ for $\mathrm{CH}_{4}$ in water, at $25^{\circ} \mathrm{C}$; and $2.6 \times 10^{-9} \mathrm{~m}^{2} / \mathrm{s}$ for $\mathrm{CH}_{4}$ in water, at $40^{\circ} \mathrm{C}$.

Regarding the good modeling of data obtained through the method of pressure decay, one of the main points and source of errors is the appropriate 
Table 2. Diffusivity coefficients $\left(D_{A B}\right)$ for different authors.

\begin{tabular}{|c|c|c|c|c|c|}
\hline Authors & $\begin{array}{l}\text { Zhang et al. } \\
\qquad(2000)\end{array}$ & $\begin{array}{c}\text { Zhang et al. } \\
\qquad(2000)\end{array}$ & $\begin{array}{l}\text { Sachs } \\
\text { (1998) }\end{array}$ & $\begin{array}{l}\text { Sachs } \\
\text { (1998) }\end{array}$ & $\begin{array}{l}\text { Riazi } \\
\text { (1996) }\end{array}$ \\
\hline System & $\mathrm{CH}_{4}-\mathrm{OIL}$ & $\mathrm{CO}_{2}-\mathrm{OIL}$ & $\mathrm{CH}_{4}$-WATER & $\mathrm{CH}_{4}$-WATER & $\mathrm{CH}_{4}-\mathrm{nC}_{5}$ \\
\hline $\begin{array}{l}\text { Inicial Pressure } \\
(\mathrm{MPa})\end{array}$ & 3.5 & 3.5 & 8.2 & 7.9 & 10.2 \\
\hline $\begin{array}{l}\text { Temperature } \\
\left({ }^{\circ} \mathrm{C}\right)\end{array}$ & 21 & 21 & 25 & 40 & 37.8 \\
\hline $\begin{array}{l}\mathrm{D}_{\mathrm{AB}} \times 10^{-9} \mathrm{~m}^{2} / \mathrm{s} \\
\text { experimental }\end{array}$ & 8.6 & 4.8 & 1.4 & 2.6 & 15 \\
\hline $\mathrm{D}_{\mathrm{AB}} \times 10^{-9} \mathrm{~m}^{2} / \mathrm{s}$ & & & & & \\
\hline $\begin{array}{l}\text { Civan and } \\
\text { Rasmussen } \\
\text { (2003) }\end{array}$ & 0.5 & 4.9 & 1.4 & 2.6 & 0.66 \\
\hline
\end{tabular}

boundary condition choice that governs the phenomenon at the interface of liquid and gas phases. The necessity of understanding the choice of this boundary condition depends on the system used, as stated by Tharanivasan et al. (2004). The researchers emphasized that the choice of boundary condition $(B C)$ in the gas-liquid interface affects the quality of interpretation of experimental data.

In this context, Tharanivasan et al. (2004) investigated the effects of boundary conditions at the interface on the diffusivity coefficient using the pressure decay method. The authors used the Fick's Law with continuity equation, as it can be seen in Equation 3, as the fundamental equation. They also tested three different boundary conditions at the interface, as follows:

$$
\frac{\partial c}{\partial t}=D \frac{\partial^{2} c}{\partial x^{2}}
$$

- Equilibrium boundary condition- it is assumed that the interface is saturated with the gas under equilibrium pressure at all times;

$$
\left.c(x, t)\right|_{x=L}=c_{s a t}\left(P_{e q}\right) \therefore t>0
$$

- Quasi-equilibrium boundary condition- the interface is saturated with the gas under the actual pressure of gas phase rather than equilibrium pressure. This pressure decays with time until the equilibrium pressure is reached;

$\left.c(x, t)\right|_{x=L}=c_{\text {sat }}[P(t)] \therefore t>0$

- Non-equilibrium boundary condition- the gas mass flux at the interface is proportional to the difference between the saturation concentration (under equilibrium pressure) and actual concentration at the interface.

$$
\left.D \frac{\partial c}{\partial x}\right|_{x=L}=k\left[c_{s a t}\left(P_{e q}\right)-\left.c(x, t)\right|_{x=L}\right] \therefore t>0
$$




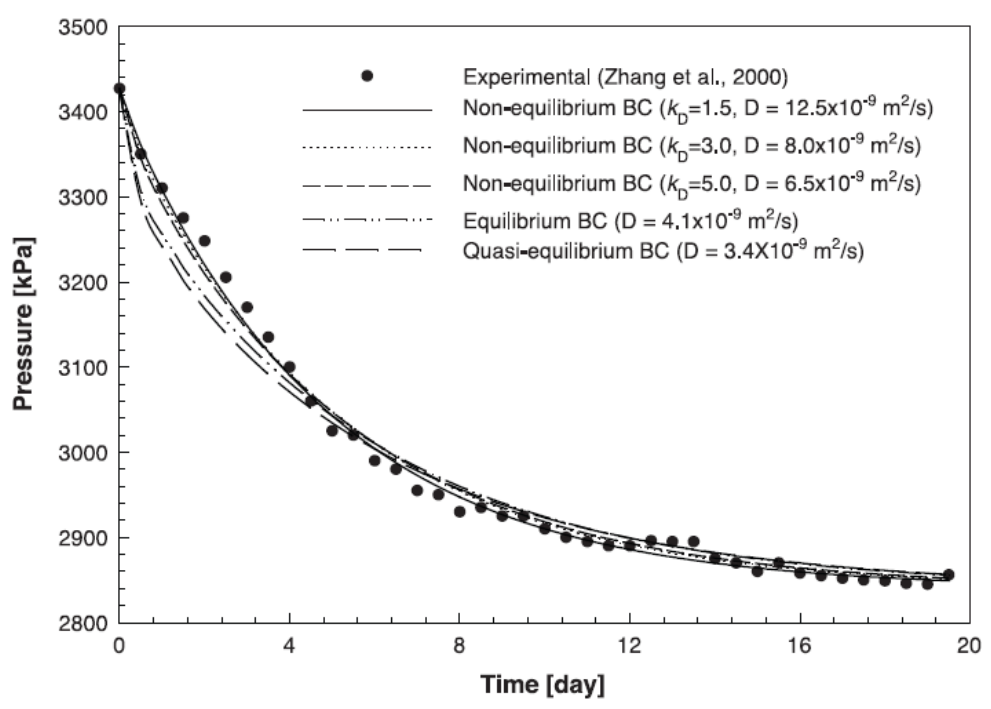

Figure 3. Pressure as a function of time for the three different boundary conditions (equilibrium, quasi-equilibrium, and non-equilibrium) at interface with Zhang's et al. (2000) experimental data for $\mathrm{CO}_{2}$-oil (Tharavanisan et al., 2004).

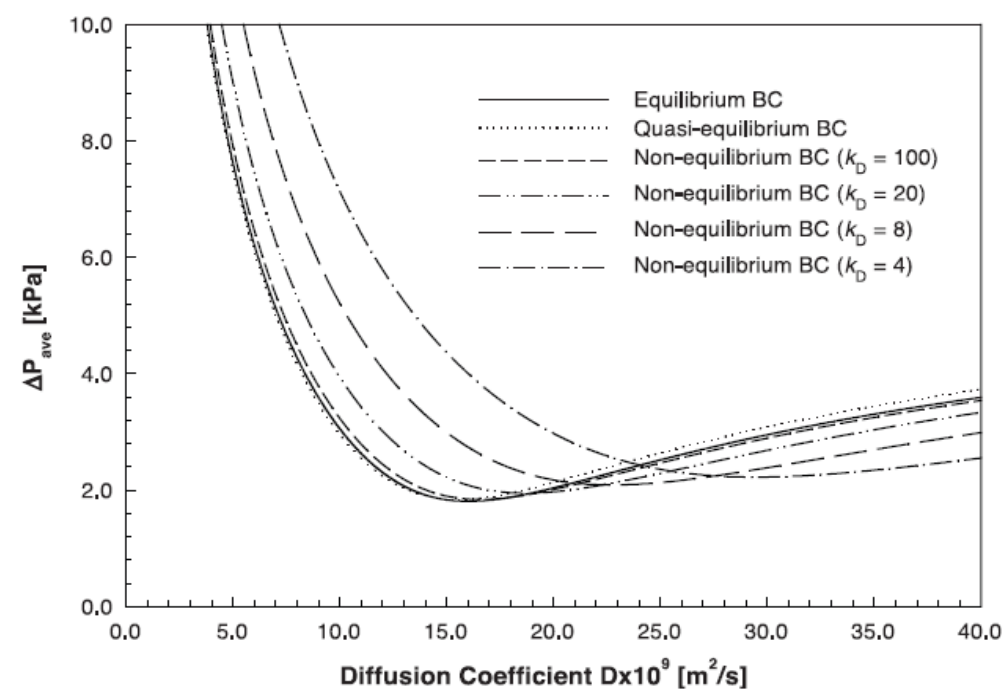

Figure 4. $\Delta P_{\text {ave }}$ as a function of $D$ for methane-heavy oil at $21{ }^{\circ} \mathrm{C}$ and $3420 \mathrm{kPa}$ (Tharanivasan et al., 2004).

where $L$ is the liquid phase height, $c_{\text {sat }}$ is the gas saturation concentration or solubility, $P_{e q}$ is the equilibrium pressure, $k$ is the mass transfer coefficient, and $D$ is the diffusivity.

As stated by the authors, the most suitable boundary condition for the $\mathrm{CO}_{2}$-heavy oil system was the non-equilibrium condition. This conclusion can be seen in Figure 3 by observing that the experimental data from Zhang et al. (2000) best fit curves in a non-equilibrium condition. Nevertheless, for methane-heavy oil system, it is more appropriate the equilibrium boundary condition as shown by Figure 4 , where $\Delta \mathrm{P}_{\text {ave }}$ is the average pressure difference between the calculated and measured pressures that corresponds to the objective function. The better value of diffusivity coefficient should be one in which $\Delta \mathrm{P}_{\text {ave }}$ is a minimum. Although the nonequilibrium condition with a Biot number $\left(k_{D}\right)$ equals to 100 and also shows a small $\Delta \mathrm{P}_{\text {ave, }}$ physically a large value of $k_{D}$ represents that there is not resistance to mass transfer at interface meaning the equilibrium situation. This is justified 


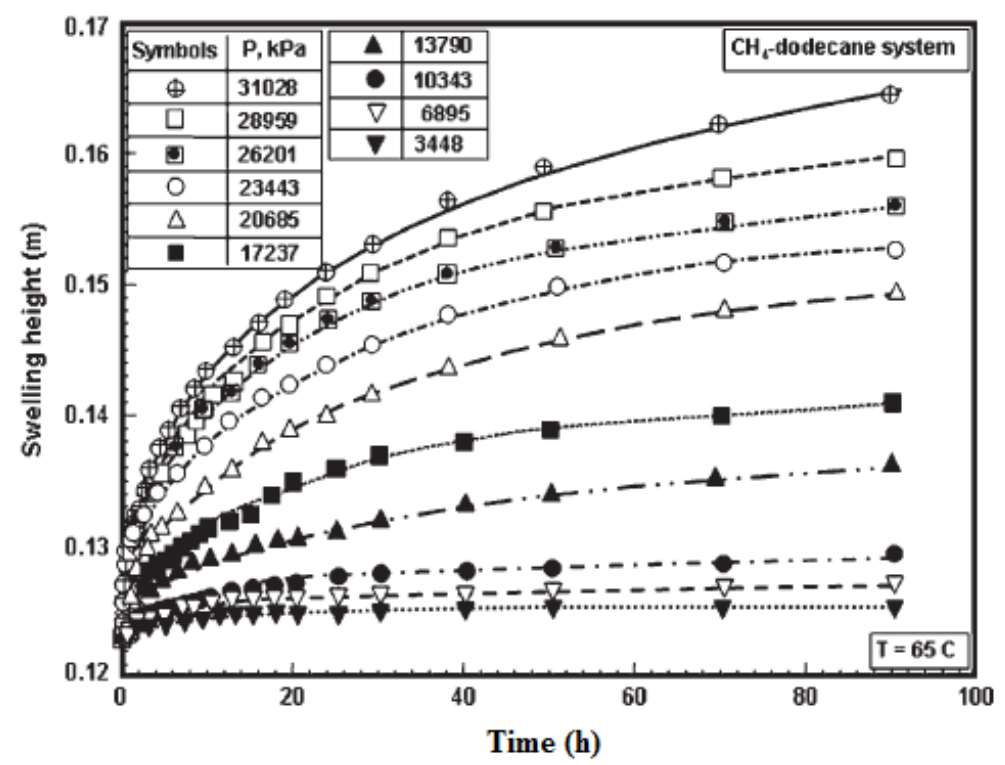

Figure 5. Height of liquid phase as a function of time and pressure for the methane-dodecane system obtained by Jamialahmadi et al. (2006).

by instantaneous saturation of methane into heavy oil due to the similarity of chemical nature. The diffusivity for the methane-heavy oil system is $16.1 \times 10^{-9} \mathrm{~m}^{2} / \mathrm{s}$ at a pressure of $3420 \mathrm{kPa}$, and at $21^{\circ} \mathrm{C}$. Finally, as noted, the choice of boundary condition at the interface of the system influences, in fact, the value of diffusivity.

\subsubsection{Other Approaches}

The pressure decay (PD) method is the most frequently used by many researchers working on the determination of gas-liquid diffusivities because of the mentioned reasons. A variation of the PD method is the volume of dissolved gas at constant pressure (CPDGV) method, which has been used for some authors like Jamialahmadi et al. (2006) and Etminan et al. (2010). This method also uses a PVT cell to obtain the experimental data and, hence, the diffusivity coefficient of gas-liquid systems. In this case, the volume changes as a function of time are recorded and temperature and pressure are kept constant with the injection of some fluid.

To perform the PD method, it is possible to use any PVT cell but, for the CPDGV method, the cell must own visual windows and a cathetometer to permit volume readings. For this reason, the PD method is preferred because of its simplicity in experimental measurements. In the other hand, according to Etminan et al. (2010), the mathematical modeling, mainly at the interface, in the PD method is more complex than in the CPDV method due to pressure decline.

Jamialahmadi et al. (2006) have worked in this research line to understand the mechanisms involved in diffusion processes of enhanced oil recovery. The investigators studied two systems, methane-dodecane and methane-Iranian crude oil, at pressures up to $35 \mathrm{MPa}$ (5000 psi) and temperatures up to $81^{\circ} \mathrm{C}$. The typical curves obtained by this method can be seen in Figure 5 for methane-dodecane system for pressures ranging from $3.5 \mathrm{MPa}$ (500 psi) to $35 \mathrm{MPa}$ (5000 psi). The relationship between height and volume to the cell used was $1 \mathrm{~cm}^{3}$ for a change of liquid level of $1 \mathrm{~mm}$.

Jamialahmadi et al. (2006) also studied the effect of solute concentration and solution viscosity on the diffusivity coefficient. It is known that the dissolution of a gas in a liquid reduces its viscosity, density, and surface tension. All these properties were calculated through Peng-Robinson equation of state, which was tuned with solubility data measured. The behavior of viscosity and density for the methane-dodecane system, observed by the investigators, can be seen in Figure 6 . It can be noted that the results presented in this work are important for understanding the 


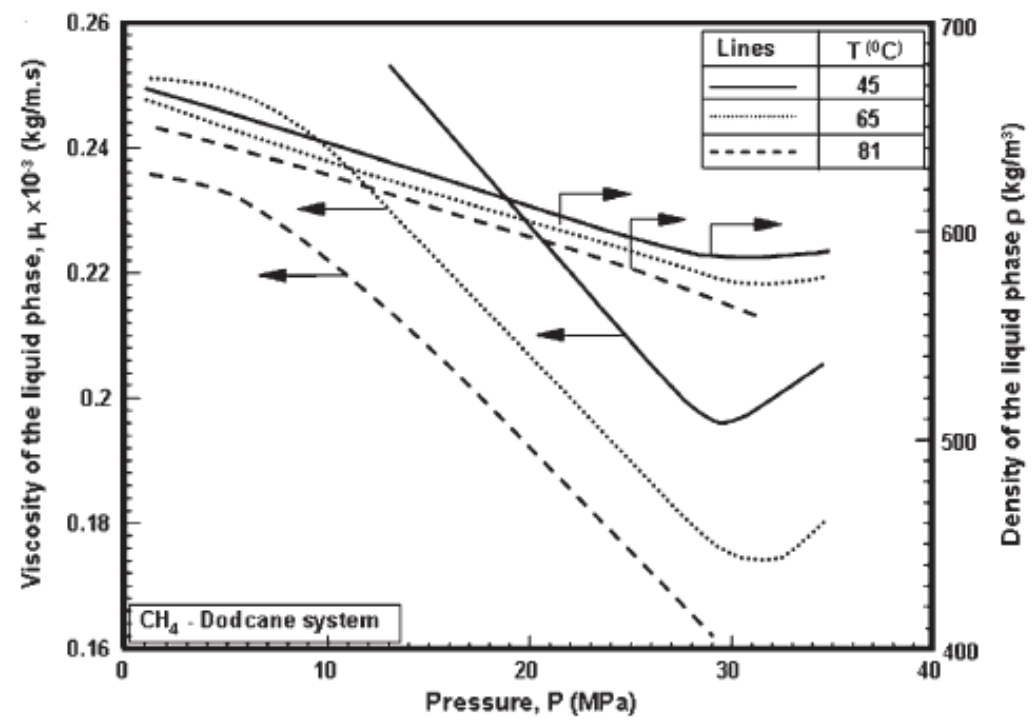

Figure 6. Solution viscosity and density as a function of pressure for the methane-dodecane system (Jamialahmadi et al., 2006).

methane-n-paraffin behavior used in ongoing tests at Unicamp. This kind of system is common in drilling operations using synthetic-based drilling fluid.

It was observed from the Figure 6 that both viscosity and density of the solution decrease with increasing pressure and temperature, until the maximum quantity of dissolved methane is reached. At this point, there is a reversal of behavior, that is, viscosity and density of the solution begin to increase gradually. This behavior is caused by the supersaturation of the solution. As a result, the diffusivity coefficient initially increases until the point of inversion. The increase in viscosity and density of the solution causes the decrease of diffusivity. Figure 7 shows the behavior of the diffusivity coefficient with pressure for methane-dodecane system. To calculate the diffusion coefficient as a function of viscosity, the investigators used the following correlation:

$$
D(T, P)=a_{0} \mu^{a_{1}}
$$

where $a_{0}$ e $a_{1}$ are parameters obtained from experimental data.

Figure 8 shows the variation of the diffusivity as a function of both liquid phase viscosity and temperature for methane-dodecane system. It can be noted that if liquid phase viscosity decreases as a result of temperature increase, gas diffusivity increases.

Jamialahmadi et al. (2006) concluded that the maximum value of diffusivity coefficient is observed at the pressure in which the gas phase disappears, that is, at the moment when all the gas is dissolved in the liquid phase. Beyond this, an increase in pressure causes an increase in viscosity and density of liquid phase and, hence, a decrease in diffusivity coefficient.

The majority of the published works from the petroleum area are concerned about diffusion problems related to oil recovery. Although this work is focused in drilling, the methodologies presented by those works to calculate diffusion coefficient can be useful in understanding diffusion processes at the drilling, since there are few works related to this operation. In this context, it can be mentioned Bodwadkar (1990), Bodwadkar and Chenevert (1997), Bladley et al., (2002), and Silva and Lomba (2007).

There are two ways in which gas formation can enter into the wellbore during drilling. According to Silva and Lomba (2007), this can happen when the well is operated at either an underbalanced or an overbalanced condition. At underbalanced conditions, the formation pressure is higher than the fluid pressure and, if there is a gas-bearing zone under this condition, a gas migration into the 


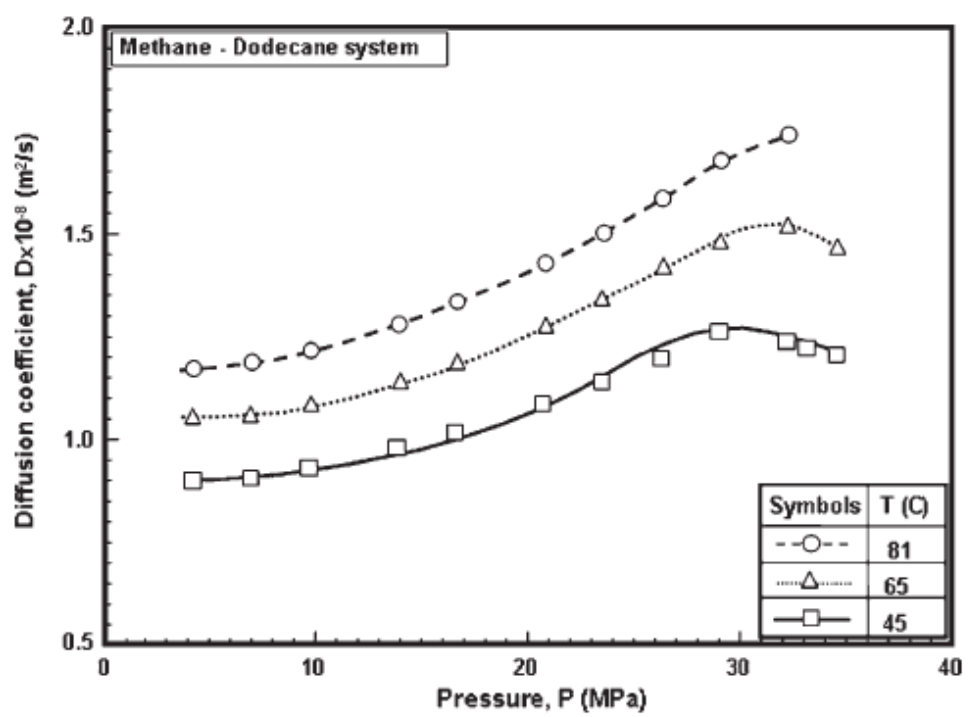

Figure 7. Diffusivity coefficient of methane in dodecane as a function of pressure and temperature (Jamialahmadi et al., 2006).

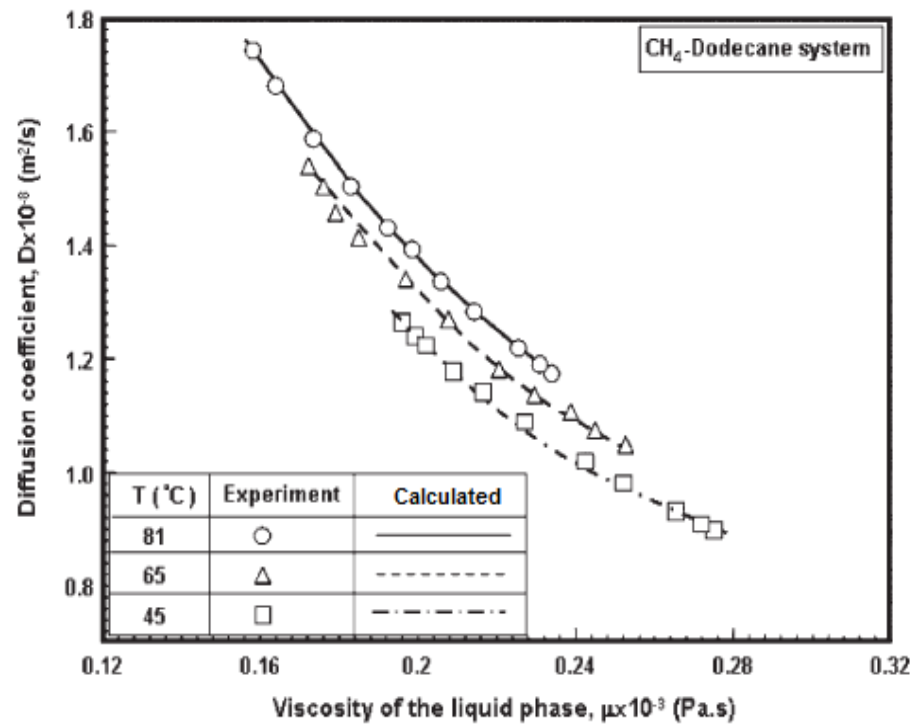

Figure 8. Diffusivity coefficient of methane in dodecane as a function of phase liquid viscosity and temperature (Jamialahmadi et al., 2006).

wellbore can occur causing a kick. Another mechanism is the invasion of gas from formation to the wellbore through the filtrate at an overbalanced condition (the well's pressure is higher than the formation pressure), when the well is static for a long period of time. If the well is under this situation for a long period of time, the volume of gas entering the well may also be sufficient to cause a kick.

In the work by Silva and Lomba (2007) it was pointed out that mechanisms of pit gain (volume increase in the drilling fluid tanks) and flow rate increase during drilling are factors that can indicate formation influx. The mechanisms mentioned by the authors were gas solubility, gas diffusion through the filter cake, gas migration (how the gas flows in the annular until reaches the surface), and thermal expansion. Knowing the mechanisms can help diagnosing the real cause of pit gain, avoiding interpretation mistakes.

Bodwadkar (1990) studied the diffusive transport of gas in oil-based drilling fluid under overbalanced condition. The oil-based drilling fluid was chosen by the author due to the gas diffusion being much higher in oil-based fluids than in waterbased fluids as a consequence of solubility effects. 


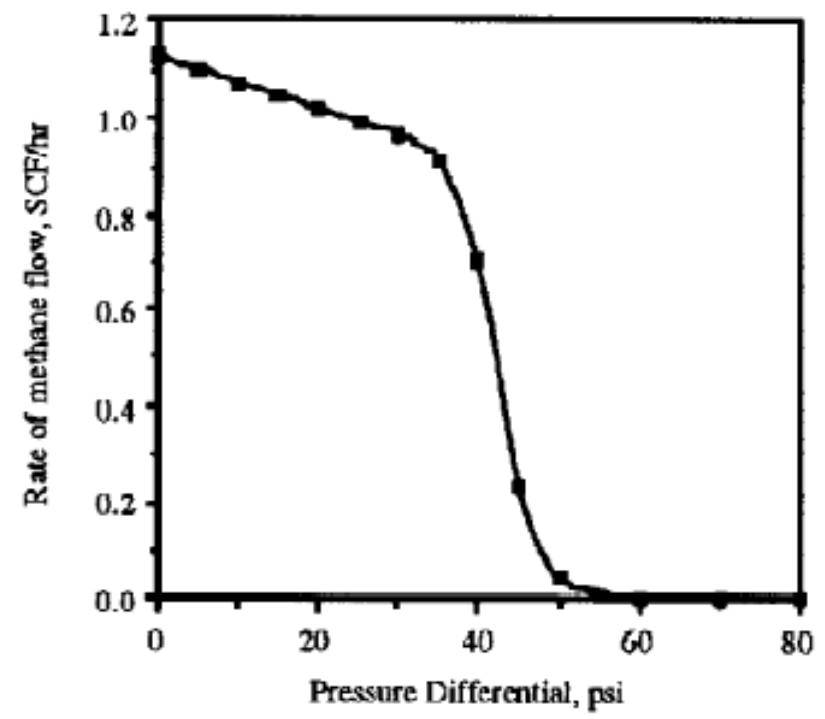

Figure 9. Rate of methane flow as a function of pressure differential (Bodwadkar and Chenevert, 1997).

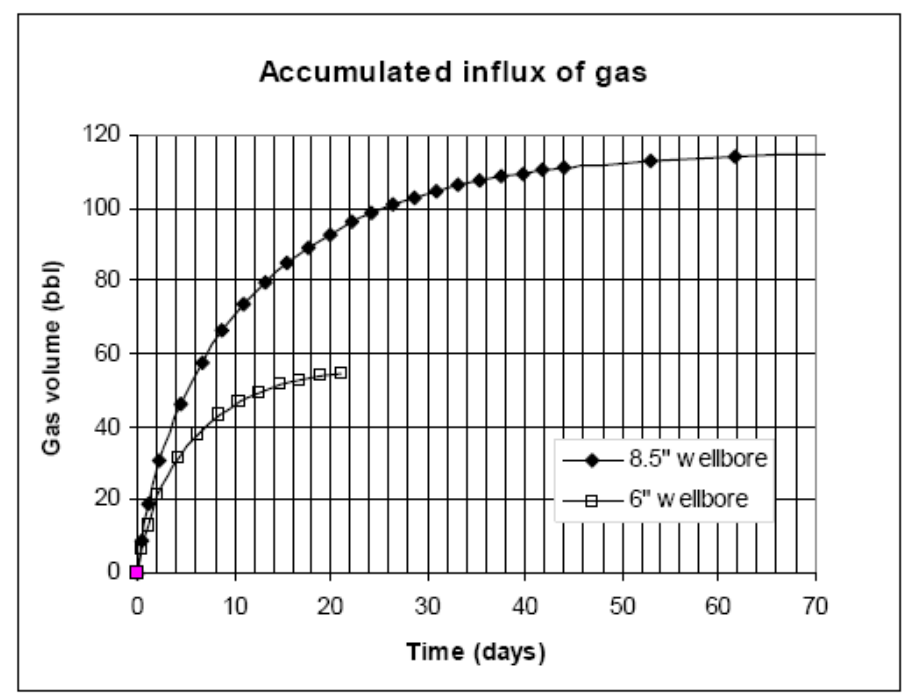

Figure 10. Accumulated volume of methane in the well as a function of time for an HPHT horizontal well (Bradley et al., 2002).

When the oil-based drilling fluid is used, all the gas can be dissolved in it at HPHT (high pressure and high temperature) and, because of this, the kick detection is more difficult (Monteiro et al., 2009). Thus, the knowledge of diffusion rates can be useful to distinguish the sources of gas from the well, and this reflects the cost of maintaining the drilling fluid. Bodwadkar (1990) stated that the diffusion rate of gas is controlled by the diffusivity coefficient in the filtrate.

The main goal of the work of Bodwadkar (1990) was to quantify how much formation gas could enter in the wellbore through the wall (mud cake) due to diffusion. And for that, laboratory tests were performed at varying pressures and temperatures. The experimental apparatus consisted of a chromatograph for compositional analysis, that is, to determine the concentration of methane that diffuses through the filter cake, and a filtration cell for diffusion tests. The cell type used was a limited high pressure and high temperature one. The system studied was composed of methane and an oil-based drilling fluid (Magcobar Drillfaze) with a density of 17 ppg (pounds-pergallon). 
The pressure and temperature of the tests ranged from 1724 to $8618 \mathrm{kPa}$, and from 38 to $149^{\circ} \mathrm{C}$, respectively. The mathematical model used by the author is based on Eq. (3) which is the fundamental equation of diffusion in onedimension. The diffusion coefficients were determined by comparing the theoretical and experimental concentration rate data graphically. For the system studied, the diffusivity coefficient obtained ranged from $2 \times 10^{-5}$ to $9 \times 10^{-5} \mathrm{~cm}^{2} / \mathrm{s}$. Bodwadkar (1990) concluded that the gas diffusion into the wellbore using oil-based drilling fluid is meaningful only when the pressure differential is between 0 and 35 psi. After this point, the gas is pushed back by the mud cake due to convection and, hence, the amount of gas into the wellbore is reduced. This can be observed in Figure 9 .

Also in this context, Bradley et al. (2002) carried out tests in a horizontal well under HPHT conditions to quantify also the amount of formation gas which enters into the wellbore when the well is under a static situation. They showed that $17,5 \mathrm{~m}^{3}$ of methane were accumulated into the wellbore when the well was static for 50 days. Figure 10 displays the accumulated volume of methane in the wellbore as a function of time. The pressure and temperature of the test performed was $72395 \mathrm{kPa}$ and $145^{\circ} \mathrm{C}$, respectively.

In the literature review, in a general way, both experimental methods and mathematical modeling to determine the related parameters of mass transfer of gas-liquid systems were discussed. It could be seen that it is necessary to perform experiments to determine the diffusivity coefficient due to the lack of a general correlation that can describe the phenomenon in liquid phase. Also, the diffusivity coefficient is a characteristic parameter for each pair of substances and varies according to the physical characteristics of the system, such as pressure, temperature, and viscosity. With regard to experimental methods used in the determination of diffusivity, each one of those has its peculiarities, with negative and positive points. The choice for the method that used a PVT cell was emphasized because it is a simple method and has the versatility to work in a wide range of pressures and temperatures in a controlled manner. The PVT method covers pressures up to $15,000 \mathrm{psi}$, that is, high pressures, which are characteristic of oil wells in ultra-deep waters of the sub-salt. As presented, the values of diffusivities for the systems studied obtained by the pressure decay method were satisfactory, reinforcing our choice to perform tests with methane and synthetic-based fluids. Regarding the mathematical modeling of the system, one must be careful when choosing the model mainly, when choosing boundary conditions since those conditions significantly will influence the quality of the final results. Besides the diffusivity coefficient, it is important to take into account in the modeling the parameters related to convection phenomenon involved when the system is under agitation.

The literature has indicated that there are limited kinetic data under HPHT conditions for gasliquid systems, mainly due to the limitations of the equipment used. Therefore, it is necessary to determine such data to improve the understanding of the interactions between drilling fluid and the reservoir fluid at wellbore conditions. This fact is an issue of great importance because it reflects the actual statement of the operating characteristics of drilling wells. It can be noted that experimental data can be used to implement computational models in a kick simulator, which would be very helpful in preventing this problem.

\subsection{Phase equilibrium}

The accurate determination of the mass transfer parameters demands previous knowledge of the phase behavior properties at various pressures and temperatures. Such data are used to determine the interface equilibrium between phases. There are some studies that address the determination of these parameters for various hydrocarbon systems that can be applied for our system.

Regarding the well issues mentioned above, it is important to know the solubility of the formation gas in the synthetic-based drilling fluid under reservoir conditions because it is the main mechanism that contributes to difficult the kick detection (Silva and Lomba, 2007). Moreover, the solubility is used for diffusivity calculation as noted. The solubility is calculated from the saturation pressure data obtained in a PVT cell and after modeled as a function of pressure, temperature, and gas fraction (Atolini, 2008).

During drilling, the interaction with the reservoir fluid can significantly modify the properties of the drilling fluid. The gas solubility 


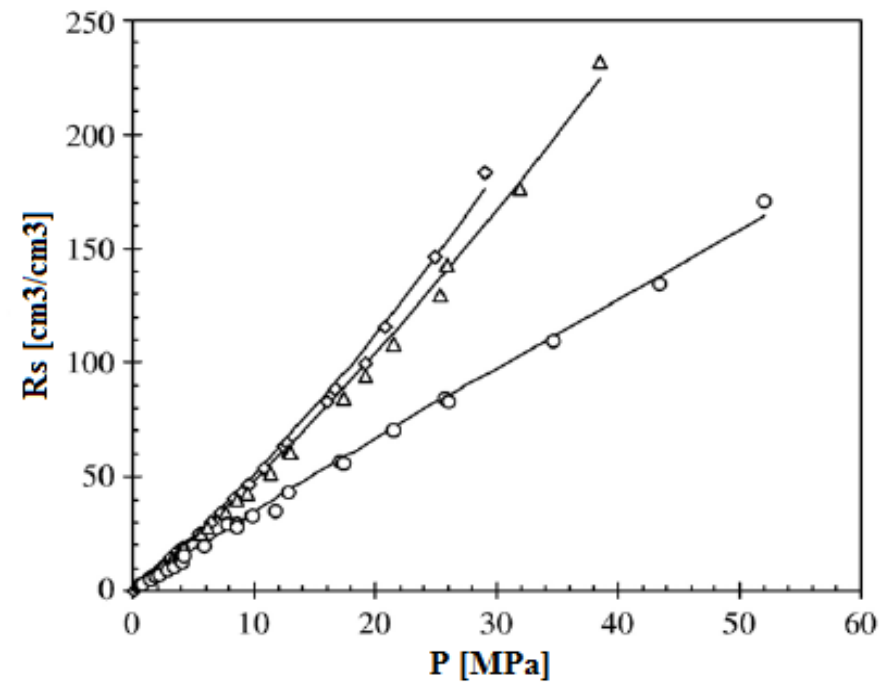

Figure 11. Methane solubility as a function of pressure at $70^{\circ} \mathrm{C}$. Legend: $\Delta-\mathrm{n}$-paraffin; $\diamond-$ iso+n-paraffin; $0-$ ester; continuous line - thermodynamic modeling (Ribeiro et al., 2006).

increase in the drilling fluid due to severe conditions of pressure, and temperature raising the risk of a gas kick. If the basis of the drilling fluid is formed by synthetic oils such as paraffins, it is expected that the gas solubility (e.g. methane) is greater than that based on water due to chemical similarity of organic compounds.

Berthezene et al. (1999) reported the thermodynamic behavior of four different types of oil-based fluids (diesel, mineral oil, synthetic oil, and oil-based ester) with methane at $90 \circ \mathrm{C}$ and pressures up to $35 \mathrm{MPa}$. The authors measured the solubility of the methane in those four oils, pure water, and water-oil emulsion to check the solubility behavior due to emulsifier presence. The Peng-Robinson equation was used for data modeling. The authors stated that the critical points for diesel, mineral oil, and synthetic oil would be located between 50 and $70 \mathrm{MPa}$. This means that under these high pressures all methane would be completely dissolved in oil phase, which would make the kick detection difficult. Furthermore, they concluded that the methane solubility in the oil phase represents the methane solubility in the drilling fluid when it is emulsified with water because gas solubility in water is very small.

Bureau et al. (2002), based on Berthezene et al.'s (1999) experiments, investigated the phase equilibrium of ester-based fluids at two different temperatures ( 363.15 and $423.15 \mathrm{~K})$ and at pressures up to $100 \mathrm{MPa}$. The researchers tested three models to preview the better data fit: PengRobinson with $\mathrm{k}_{\mathrm{ij}}=0$; Soave-Redlick-Kwong (SRK) with MHV2 mixing rule with UNIFAC, and, finally, Elliott-Surech-Donohue (ESD) with $k_{i j}=0$. It was observed that the most appropriate equation to model the case of asymmetric mixtures is the ESD equation. Based on the experiments, the authors concluded that for esters with long chains the critical point is too high, above $100 \mathrm{MPa}$, which means that the methane solubility in ester is smaller than in alkanes.

Ribeiro et al. (2006) performed experiments with methane and $n$-parrafin, ester and (iso+n)paraffin mixture aiming to understand the thermodynamic behavior of these systems. They applied pressures up to $55 \mathrm{MPa}$, for the first and third systems, and up to $70 \mathrm{MPa}$ for the second system, and temperatures of $70 \circ \mathrm{C}$ and $90 \circ \mathrm{C}$. These kinds of information can be helpful for well control procedures. To model the solubility for those systems, the authors used the KrichevskyKasarnovsky model with Henry's law correction. Like those previous authors, they confirmed that the solubility of methane in paraffins is much greater than in esters, as shown in Figure 11. They suggested the development of a computational kick simulator including that kind of thermodynamic information to improve the safety procedures of the drilling. In addition, they emphasized the necessity of carrying out more experiments in a wide range of temperatures. 


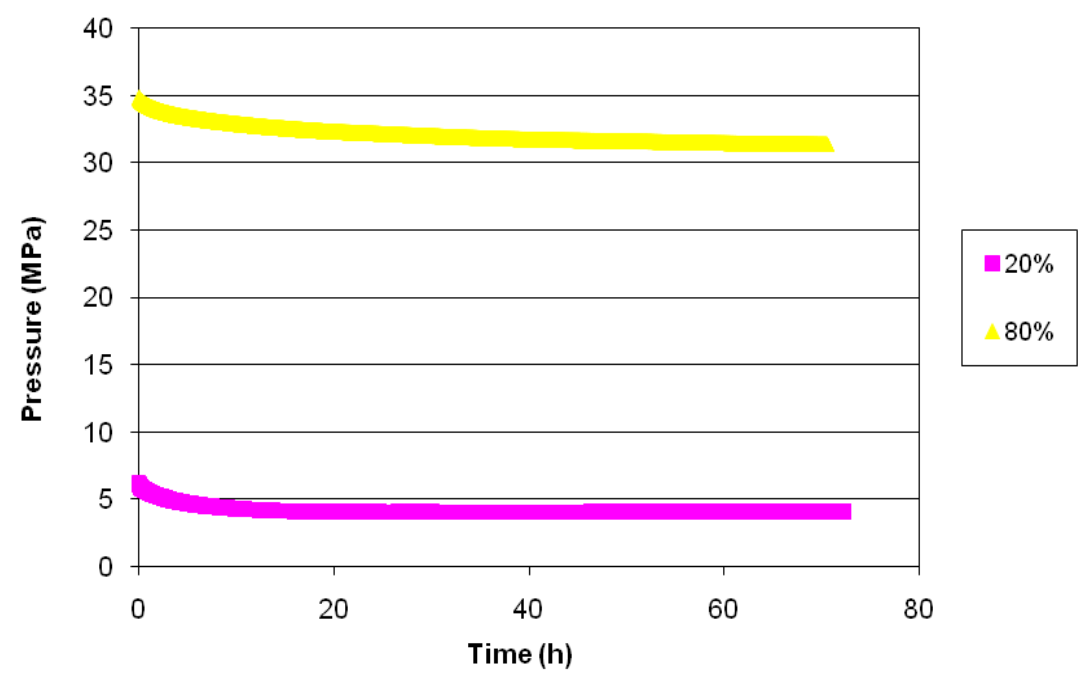

Figure 12. Pressure-time data for methane $-\mathrm{n}$-paraffin at $108.9 \circ \mathrm{C}$ and 20 and $80 \%$ of methane.

In this context, Atolini (2008) and Kim (2010) have continued Ribeiro et al.'s (2006) work. Atolini (2008) studied the thermodynamic behavior of methane-n-paraffin and methane-n-paraffin emulsions for $70-130 \circ \mathrm{C}$ temperature and $12-$ 95\% molar fraction range. From the saturation pressure data obtained, the author calculated properties for these systems such as solubility, specific gravity, and formation volume factor. Besides this, Atolini (2008) developed correlations for those properties as a function of molar fraction of methane, pressure, and temperature. The correlations obtained for emulsion were tested on the three case studies to discover the pit gain in the mud tanks. The results showed that pit gain in water-based fluids is greater than in oil-based fluids and it increases when pressure increases.

Recently, Kim (2010) investigated the interaction of methane with ester and ester emulsions as base of drilling fluid using the same range of temperature and molar fraction of methane studied by Atolini (2008) for methane $\mathrm{n}$-paraffin mixtures. The studies conducted by Kim (2010) were similar to those made by Atolini (2008). The author also obtained correlations for solubility, specific gravity, and formation volume factor from saturation pressure experimental data.

However, it can be noted that thermodynamic behavior for methane and synthetic-based drilling fluid systems were widely investigated. Those solubility correlations proposed by Atolini (2008) and Kim (2010) can be useful in diffusivity calculation for that kind of system.

\section{EXPERIMENTAL RESULTS}

Diffusive experiments have been carried out at the Petroleum Engineering Department of Unicamp. These experiments aim to obtain mass transfer parameters for gas-liquid systems under HPHT conditions applied to drilling operations.

The $\mathrm{n}$-paraffin used in the tests was provided by Petrobras. Its composition varies from C5 to C21, containing C14 (66.4291 mol\%) and C15 (25.5987 mol\%) in larger quantities. More details about the $n$-paraffin's composition can be seen in Atolini (2008).

It has been used a PVT cell $\left(100 \mathrm{~cm}^{3}, 100 \mathrm{MPa}\right.$, Schlumberger) in which diffusion cell is surrounded by a temperature-controlled air bath (-73 to $200 \circ \mathrm{C})$. The PVT cell was coupled with an automatic pump $\left(500 \mathrm{~cm}^{3}, 130 \mathrm{MPa}\right)$ and a data acquisition system. The diffusion cell was similar to the one displayed in Figure 1.

The experimental procedure was based on the pressure decay method mentioned previously. Initially, the n-paraffin was charged into the cell at the desired volume, temperature and pressure. After this, the desired amount of methane was introduced into the cell through the bottom like nparaffin was. It was assumed that this moment was 
Table 3. Experimental data for methane-n-paraffin and carbon dioxide-n-paraffin systems.

\begin{tabular}{|c|c|c|c|c|}
\hline $\mathrm{T}(\mathrm{O} \mathrm{C})$ & $\mathrm{X}_{\mathrm{CH} 4}(\%)$ & $P_{i}(\mathrm{MPa})$ & $P_{\text {eq }}(\mathrm{MPa})$ & $D\left(\mathrm{~cm}^{2} / \mathrm{s}\right)$ \\
\hline 108.9 & 20 & 6.2 & 4.0 & $0.16 \cdot 10^{-5}$ \\
\hline 70.80 & 80 & 38.1 & 32.3 & $4.02 .10^{-5}$ \\
\hline 108.9 & 80 & 34.8 & 31.3 & $8.00 .10^{-5}$ \\
\hline $\mathrm{T}$ (OC) & $\mathrm{x}_{\mathrm{CO} 2}(\%)$ & $P_{i}(\mathrm{MPa})$ & $P_{\text {eq }}(\mathrm{MPa})$ & $\mathrm{D}\left(\mathrm{cm}^{2} / \mathrm{s}\right)$ \\
\hline 69.8 & 25 & 4.0 & 3.0 & $5.7 .10^{-4}$ \\
\hline 69.8 & 50 & 8.1 & 6.8 & 2.0. $10^{-3}$ \\
\hline
\end{tabular}

so fast that no gas was dissolved in the liquid phase, so the initial concentration of gas in liquid phase was zero. At this moment, the test began and the pressure-time data was recorded online by software. The interface and total volume changes were measured manually through a cathetometer. The test was performed until the equilibrium pressure was reached.

The methane-n-paraffin has been studied and it can be seen a typical result obtained by pressure decay method in Figure 12. All initial experimental data and diffusivity coefficient obtained for this system in these conditions are shown in Table 3.

It can be noted from Table 3 that the diffusivity coefficient increased from 4.02.10 $10^{-5}$ to 8.00.10 ${ }^{5} \mathrm{~cm}^{2} / \mathrm{s}$ when temperature increased. This behavior was expected because temperature increase leads to the excitement of molecules. Besides this, when the methane molar fraction rises from 20 to $80 \%$, the diffusivity coefficient also rises. Those behaviors refer to the methane-n-paraffin system. Tests were carried out with carbon dioxide $\left(\mathrm{CO}_{2}\right)$ with the same n-paraffin, and the results can be also observed in Table 3. This system has showed the same behavior of the methane-n-paraffin one, when the gas molar fraction was increased. However, the diffusivity coefficients of carbon dioxide into $n$-paraffin were larger than methane into the same liquid medium.

The diffusivity coefficients obtained for the methane-n-paraffin system studied are similar to those reported by Bodwadkar and Chenevert (1997) that ranged from 2 to $9.10^{-5} \mathrm{~cm}^{2} / \mathrm{s}$ for methane-oil-based drilling fluid. These results indicate that the pressure decay method with PVT cell used is reliable to obtain mass transfer parameters. The mathematical modeling used to calculate diffusivity coefficient was based on Zhangh et al. (2000) as first attempt.

\section{CONCLUSIONS}

The majority of the literature available on mass transfer in the petroleum area aims to understand the behavior of gas-liquid mixtures applied to enhance oil recovery, as noted. The understanding of the mass transfer processes is a resource of important information for process modeling under reservoir conditions, along with data on the amount of solute dissolved in oil and the rate in which it occurs. Thus, it is expected that the future tests performed using the information from this study will be useful to preview the behavior of the formation gas-drilling fluid at reservoir conditions for the control of well operations' safety.

As reported, diffusivity data for gas-liquid mixtures measured by PVT cells can be obtained with reliability and velocity in a wide range of pressure and temperature without needing compositional analysis of phases. Those diffusivity data are calculated through mathematical modeling from a set pressure-time or volume-time data.

The results obtained for methane-n-paraffin and carbon dioxide-n-paraffin system were in agreement with data presented by literature. This behavior indicates that the applied experimental methodology may be reliable.

Finally, even with the publication of some works of diffusion for gas-liquid systems, there is still a lack of data at high pressures and high temperatures, where such conditions are the 
biggest challenges in the science of petroleum engineering.

\section{REFERENCES}

Atolini, T. M. Study of the PVT behavior of methane in $n$-paraffin based emulsions mixtures at high temperatures, pressures and concentrations of methane. Thesis - Unicamp, Campinas, Brazil, 2008. (in Portuguese).

Avelar, C. S., Ribeiro, P.R., Sepehrnoori, K. Deepwater gas kick simulation. J. Pet. Sci. Eng., v. 67, p. 13 - 22, 2009. doi:10.1016/i.petrol.2009.03.001

Berthezene, N., Hemptinne, J.-C., Audibert, A., Argillier, J. - F. Methane solubility in synthetic oilbased drilling muds. J. Pet. Sci. Eng., v. 23, p. 71 81, 1999. doi:10.1016/S0920-4105(99)00008-X

Bodwadkar, S. V. Diffusion of gas through oil mud filter cakes. Thesis - The University of Texas, Austin, EUA. 1990.

Bodwadkar, S. V., Chenevert, M. E. Diffusion of gas in oil based drilling fluids. SPE Production Operations Symposium Proceedings. 1997.

Bradley, N. D., Low, E., Aas, B., Rommetveit, R., Larsen, H. F. Gas diffusion - its impact on a HPHT horizontal well. SPE Annual Technical Conference and Exhibition Proceedings. 2002.

Brenner, N.; Guegel, A.; Hwee, T. H.; Pitt, A.. Coast Guards Confirms Horizon Sinks. Available at: http://www.upstreamonline.com/live/article21276 9.ece. Accessed on: 09 June 2010.

Bureau, N., Defiolle, D., Hemptinne, J. -C. Phase equilibria of (methane-long chain ester cuts) systems in drilling conditions. Fluid Phase Equilibria, v. $194-197$, p. $831-846,2002$.

Civan, F., Rasmussen, M. L. Accurate measurement of gas diffusivity in oil and brine under reservoir conditions. SPE Production Operations Symposium Proceedings. 2001.

Civan, F., Rasmussen, M. L. Improved measurement of gas diffusivity for miscible gas flooding under nonequilibrium vs. equilibrium conditions. SPE Improved Oil Recovery Symposium Proceedings. 2002.
Civan, F., Rasmussen, M. L. Analysis and interpretation of gas diffusion in quiescent reservoir, drilling and completion fluids: equilibrium vs. non-equilibrium models. Proceedings - SPE Annual Technical Conference and Exhibition. 2003.

CNN Wire Staff. Oil Spill from Rig Explosion at $\mathbf{5 , 0 0 0}$ barrels a day. Available at: http://edition.cnn.com/2010/US/04/28/louisiana.o il.rig.fire/index.html?iref=allsearch. Accessed on: 09 June 2010

Etminan, S. R., Maini, B. B., Chen, Z., Hassanzadeh, $\mathrm{H}$. Constant-pressure technique for gas diffusivity and solubility measurements in heavy oil and bitumen. Energy Fuels, v. 24, p. 533 - 549, 2010. doi: 10.1021/ef9008955

Guerrero-Aconcha, U., Kantzas, A. Diffusion of hydrocarbon gases in heavy oil and bitumen. Proceedings - SPE LACPEC. 2009.

Kim, N. R. Study of the PVT behavior of methane and ester based drilling fluids mixtures. Thesis - Unicamp, Campinas, Brazil, 2010. (in Portuguese).

Jamialahmadi, M., Emadi, M., MüllerSteinhagen, $H$. Diffusion coefficients of methane in liquid hydrocarbons at high pressure and tempearture. J. Pet. Sci. Eng., v. 53, p. 47 - 60, 2006. doi:10.1016/i.petrol.2006.01.011

Moganty, S. S., Baltus, R. E. Diffusivity of carbon dioxide in room-temperature ionic liquids. Ind. Eng. Chem. Res., v. 49, p. 9370 - 9376, 2010. doi:10.1021/ie101260j

Monteiro, E. N., Ribeiro, P. R., Lomba, R. F. T. Study of the PVT Properties of gas - synthetic-drillingfluid mixtures applied to well control. SPE Drilling \& Completion. 2009. http://dx.doi.org/10.2118/116013PA

Rasmussen, M. L., Civan, F. Parameters of gas dissolution in liquids obtained by isothermal pressure decay. Fluid Mechanics and Transport Phenomena, v. 55(1), p. 9-23, 2009. 
Renner. T.A. Measurement and correlation of diffusion coefficients for oil and rich gas applications. SPE Res. Engr., v. 3, p. 517-523, 1988.

Riazi, M. R. A new method for experimental measurement of diffusion coefficients in reservoir fluids. J. Pet. Sci. Eng., v. 14, p. 235 - 250, 1996. doi:10.1016/0920-4105(95)00035-6

Ribeiro, P. R., Pessôa-Filho, P. A., Lomba, R. F. T., Bonet, E. J. Measurement and modeling of methane dissolution in synthetic liquids applied to drilling fluid formulation for deep and ultradeep water Wells. J. Pet. Sci. Eng., v. 51, p. $37-44$, 2006. doi:10.1016/i.petrol.2005.11.007

Sachs, W. The diffusional transport methane in liquid water: method and result of experimental investigation at elevated pressure. J. Pet. Sci. Eng., v. 21 , p. $153-164,1998$.

Sheikha, H., Pooladi-Darvish, M., Mehrotra, A. K. Development of graphical methods for estimating the diffusivity coefficient of gases in bitumen from pressure-decay data. Energy \& Fuels, v. 19, p. 2041 - 2049, 2005.

Silva, R. A., Lomba, R. F. T. Mecanismos de ganho de volume na perfuração com fluidos nãoaquosos. In: Encontro Nacional de Hidráulica de Poços (ENAHPE), Proceeding ENAHPE 2007, Rio de Janeiro, 2007. (in Portuguese).
Tharanivasan, A. K., Yang, C., Gu, Y. Comparison of three different interface mass transfer models used in the experimental measurement of solvent diffusivity in heavy oil. J. Pet. Sci. Eng., v. 44, p. 269 - 282, 2004. doi:10.1016/i.petrol.2004.03.003

Upreti, S. R. Experimental measurement of gas diffusivity in bitumen: results for $\mathrm{CO}_{2}, \mathrm{CH}_{4}, \mathrm{C}_{2} \mathrm{H}_{6}$, and $\mathbf{N}_{2}$. Thesis - The University of Calgary, Calgary, 2000 .

Wen, Y. W., Kantzas, A. Monitoring bitumensolvent interactions with low-field nuclear magnetic resonance and $\mathrm{x}$-ray computer-assisted tomography. Energy \& Fuels, v. 19, p. $1319-1326$, 2005.

Yang, C., Gu, Y. New experimental method for measuring gas diffusivity in heavy oil by the dynamic pendant drop volume analysis (DPDVA). Ind. Eng. Chem. Res., v. 44, p. 4474-4483, 2005.

Zhang, Y. P., Hyndman, C. L., Maini, B. B. Measurement of gas diffusivity in heavy oils. J. Pet. Sci. Eng., v. 25, p. $37-47$, 2000. doi:10.1016/\$09204105(99)00031-5 